\title{
Molecular Basis of Selective IgG2 Deficiency The Mutated Membrane-bound Form of $\gamma 2$ Heavy Chain Caused Complete IgG2 Deficiency in Two Japanese Siblings
}

Hideaki Tashita, Toshiyuki Fukao, Hideo Kaneko, Takahide Teramoto, Ryosuke Inoue, Kimiko Kasahara, and Naomi Kondo Department of Pediatrics, Gifu University School of Medicine, Gifu, Gifu 500-8076, Japan

\begin{abstract}
Patients with IgG2 deficiency have recurrent sinopulmonary infections caused by Pneumococcus and Hemophilus. Hereditary and selective IgG2 deficiency was suspected in two Japanese siblings whose serum IgG2 levels were under detection limits, while other serum levels of immunoglobulin subclasses were within normal ranges. Expression level of spontaneous germline $\mathrm{C} \gamma 2$ transcript was normal, but that of the spontaneous mature $\mathrm{C} \gamma 2$ transcript was greatly decreased in the patients' PBMCs, suggesting the presence of a defect at or after the class switch to $\mathrm{C} \gamma 2$. We sequenced the $\mathrm{C} \gamma 2$ gene region, and in both patients a homozygous one-base insertion (1793insG) was present in exon 4 of the C $\gamma 2$ gene, just upstream from the alternative splice site for $M$ exons. The mutant membrane-bound $\gamma 2$ heavy chain loses the transmembrane domain and the evolutionarily conserved cytoplasmic domain. Considering several lines of evidence showing that intact expression of the membranebound heavy chain is essential for a normal response of $B$ cells and production of secreted immunoglobulin in mice, we concluded that 1793insG is responsible for selective and complete IgG2 deficiency in these two siblings. This is the first documentation of a mutation in human selective IgG2 deficiency. (J. Clin Invest. 1998. 101:677-681.) Key words: immunodeficiency $\cdot$ mutation $\cdot$ alternative splicing $\cdot \mathbf{M}$ exon • IgG subclass
\end{abstract}

\section{Introduction}

The $\mathrm{B}$ cell antigen receptor $(\mathrm{BCR})^{1}$ initially expressed on $\mathrm{B}$ cells consists of membrane-bound immunoglobulin made up of $\mu$ heavy $(\mathrm{H})$ chains plus light chains associated with the $\mathrm{Ig}-\alpha-$ Ig- $\beta$ heterodimer (1). When B cells are stimulated with antigen, they often undergo isotype switching leading to expression of $\mathrm{H}$ chains of other classes. These other $\mathrm{H}$ chains are

Address correspondence to Toshiyuki Fukao, M.D., Ph.D., Department of Pediatrics, Gifu University School of Medicine, 40 Tsukasamachi, Gifu, Gifu 500-8076, Japan. Phone: 81-58-265-1241 (ext. 2817); FAX: 81-58-265-9011; E-mail: toshi-gif@umin.u-tokyo.ac.jp

Received for publication 8 September 1997 and accepted in revised form 1 December 1997.

1. Abbreviations used in this paper: $\mathrm{BCR}, \mathrm{B}$ cell antigen receptor; $\mathrm{H}$ chain, heavy chain; m $\gamma 2 \mathrm{HC}$, membrane-bound $\gamma 2$ heavy chain; RT, reverse transcription; s $\gamma 2 \mathrm{HC}$, secreted form of $\gamma 2 \mathrm{H}$ chain.

J. Clin. Invest.

(C) The American Society for Clinical Investigation, Inc. 0021-9738/98/02/0677/05 \$2.00

Volume 101, Number 3, February 1998, 677-681

http://www.jci.org present in secreted antibodies, and can also be expressed as a component of the BCR on the cell surface (2). The membranebound forms of $\gamma, \epsilon$, and $\alpha \mathrm{H}$ chains differ from those of $\mu$ and $\delta$ in that they possess cytoplasmic tails of $28(\gamma, \epsilon)$ and $14(\alpha)$ amino acids, which have been highly conserved throughout evolution. Membrane-bound immunoglobulin expression is essential for generation of efficient primary and secondary immunoglobulin responses. The primary immunoglobulin response as well as the expansion, maintenance, or both, of immunoglobulin-bearing memory B cells, depends strongly on the cytoplasmic tail of the heavy chain in mice (3-5).

IgG subclass deficiency is an immunodeficiency associated with the absence or severe reduction in the level of one or two subclass(es), but with normal or increased levels of other subclass(es). Only a homozygous deletion of the Ig H chain constant region genes has been found in some patients with IgG subclass deficiencies (6). The molecular basis of selective IgG2 deficiency has not been defined. We investigated molecular events of selective and complete IgG2 deficiency in two Japanese siblings in whom serum $\mathrm{IgG} 2$ levels were retained under the detection limit for at least $4 \mathrm{yr}$; some transient IgG2-deficient children show normalization without therapy (7). We identified a homozygous 1793insG mutation in Cy2 exon 4, which resulted in loss of the transmembrane domain and the evolutionarily conserved cytoplasmic domain in a membranebound $\gamma 2$ heavy chain $(\mathrm{m} \gamma 2 \mathrm{HC})$.

\section{Methods}

Case presentation. The proband (5-yr-old boy) and his elder brother (10 yr old), both Japanese, were examined. The parents were not consanguineous. Otitis media and respiratory infection such as pneumonia had occurred repeatedly in both patients. Serum IgG2 was undetectable $(<2.7 \mathrm{mg} / \mathrm{dl})$, and the levels of other immunoglobulins, including other IgG subclasses, were practically normal in both patients. The specific IgG2 antibody to Streptococcus pneumoniae was also undetectable. The $\mathrm{IgG} 2$ level in the mother was within a normal range. Samples from the father were not available.

Serum IgG subclass level. The serum IgG subclass levels were measured, using ELISA as described (8). We used highly purified monoclonal antibodies against each of the four human IgG subclasses (HP6012 for IgG1, HP6014 for IgG2, HP6050 for IgG3, and HP6011 for $\mathrm{IgG} 4$, as recommended by the World Health Organization).

$R N A$ preparation and reverse transcription. PBMCs were isolated from heparinized blood by gradient centrifugation in FicollPaque (Pharmacia Fine Chemicals, Uppsala, Sweden). Total cellular RNA was extracted from the $1.0 \times 10^{6}$ PBMCs using Isogen (Nippon Gene, Tokyo, Japan). Total RNA was reverse transcribed at $37^{\circ} \mathrm{C}$ for 60 min with $200 \mathrm{U}$ of MMLV reverse transcriptase (GIBCO-BRL, Gaithersburg, MD), and $30 \mathrm{ng}$ of oligo d(T) primer in $20 \mu 1$ of $50 \mathrm{mM}$ Tris- $\mathrm{HCl}$ ( $\mathrm{pH} 8.3$ ), $75 \mathrm{mM} \mathrm{KCl,} 3 \mathrm{mM} \mathrm{MgCl}, 10 \mathrm{mM}$ DTT, $1 \mathrm{mM}$ dNTPs, and $20 \mathrm{U}$ of RNase inhibitor (Pharmacia Fine Chemcials).

Preparation of a Sty I fragment for competitor DNA. PCR amplification of interleukin-12 receptor cDNA (9) was carried out with flanking primers and cycling conditions as follows: forward, $5^{\prime}$ ${ }^{13}$ tcgcaggtggcagagaggct-3'; reverse, $5^{\prime}-{ }^{1296}$ TCCTGCCCCATTGCC- 


\begin{tabular}{|c|c|c|c|c|c|}
\hline Name & Direction & Sequence $\left(5^{\prime}\right.$ to $\left.3^{\prime}\right)$ & Position & Target & Reference \\
\hline IS1 & sense & ${ }^{954}$ tctcagccaggaccaaggac & $\mathrm{I} \gamma 2$ & germline $\mathrm{C} \gamma 2$ transcript & 10 \\
\hline HA1 & antisense & ${ }^{922}$ ACTCGACACAACATTTGCG & $\mathrm{C} \gamma 2$ exon 2 (hinge) & germline and mature $\mathrm{C} \gamma 2$ transcripts & 11 \\
\hline JHS & sense & ${ }^{1940}$ CCTGGTCACCGTCTCCTCA & $\mathrm{JH}$ region & mature $\mathrm{C} \gamma 2$ transcript & 12 \\
\hline \multirow[t]{2}{*}{ HS } & sense & ${ }^{892}$ ctctctgcagAGCGCAAATGTT- & & & \\
\hline & & GTGTCGAG & C $\gamma 2$ exon 2 (hinge) & C $\gamma 2$ fragment (for Sma I digestion) & 11 \\
\hline MA & antisense & ${ }^{217}$ ggccetggacaccccgcagagggtgn* & common $\mathrm{M}$ exon sequence & $\gamma 2 \mathrm{M}$ exons & 14,15 \\
\hline CS1 & sense & gggggaatt ${ }^{17} \mathrm{ccgggcctgactttggcttt}$ & upstream from $\mathrm{C} \gamma 2$ exon 1 & $\mathrm{C} \gamma 2$ & 11 \\
\hline CA & antisense & tcagaat ${ }^{1976}$ tcagactcggectgacccac & downstream from $\mathrm{C} \gamma 2$ exon 4 & $\mathrm{C} \gamma 2$ & 11 \\
\hline CS2 & sense & ${ }^{1929} \mathrm{cccctgcgagactg}$ tgatggttctttccgt & downstream from $\mathrm{C} \gamma 2$ exon 4 & $\gamma 2 \mathrm{M}$ exons & 11 \\
\hline IS2 & sense & ${ }^{740}$ ggggcttccaagccaacagggcaggaca & $\mathrm{I} \gamma 2$ & ly 2-C 2 fragment (first PCR) & 10 \\
\hline \multirow[t]{2}{*}{ HA2 } & antisense & ${ }^{933}$ GCACGGTGGGCACTCG- & & & \\
\hline & & ACACAACATTTGCG & C $\gamma 2$ exon 2 (hinge) & $1 \gamma 2-C \gamma 2$ fragment (first PCR) & 11 \\
\hline SS & sense & ${ }^{1350}$ gacgggaggatctgggagctcac & downstream from $3^{\prime} \mathrm{I} \gamma 2$ border & Sy 2 (second PCR) & 10 \\
\hline SA & antisense & ${ }^{72}$ ctcagtgggatgggctcacactccettcct & inverted repeat of $5^{\prime} \mathrm{S} \gamma 2$ segment & Sy 2 (second PCR) & 10 \\
\hline
\end{tabular}

Oligonucleotide sequences for $\gamma 2$-specific amplification. de novo Eco RI site was introduced CS1 and CA primers for cloning $($ underlined). * $\mathrm{n}=\mathrm{A}$, $\mathrm{G}, \mathrm{C}$, or T.

CCAGA- $3^{\prime}$; $95^{\circ} \mathrm{C}$ for $1 \mathrm{~min}, 60^{\circ} \mathrm{C}$ for $1 \mathrm{~min} 30 \mathrm{~s}$, and $72^{\circ} \mathrm{C}$ for $3 \mathrm{~min}$ for 35 cycles. The product is $1284 \mathrm{bp}$ in length and yields the expected 113 bp, 191 bp, 233 bp, 348 bp, and 399 bp fragments after Sty I digestion. The 233-bp fragment was separated by polyacrylamide-gel electrophoresis, and purified.

Oligomers used in following experiments. Fig. 1 schematically shows the locations of oligomers in the regions of $\mathrm{JH}, \mathrm{I} \gamma 2, \mathrm{~S} \gamma 2, \mathrm{C} \gamma 2$, and $\mathrm{M}$ exons. Table I shows sequences of oligomers and some information. The nucleotide numbers on oligomers are given in the references. Capital letters were used in cases of coding sequences, and small letters were used in cases of noncoding sequences.

Quantitative PCR for germline $C \gamma 2$ transcript. PCR amplification of germline $\mathrm{C} \gamma 2$ transcript was carried out with IS1 and HA1 primers and cycling conditions $(10,11)$ as follows: $94^{\circ} \mathrm{C}$ for $45 \mathrm{~s}, 60^{\circ} \mathrm{C}$ for $1 \mathrm{~min}$, and $72^{\circ} \mathrm{C}$ for $1 \mathrm{~min} 30 \mathrm{~s}$ for 35 cycles. The plasmid containing $341 \mathrm{bp}$ cDNA from germline $\mathrm{C} \gamma 2$ transcript was partially substituted with the 233-bp Sty I fragment from interleukin-12 receptor cDNA, and was used as a competitor DNA. The PCR product of the wild-type was $341 \mathrm{bp}$, and that of the competitor was $287 \mathrm{bp}$. Each template contained the same amounts of cDNA from RNA extracted from $7.3 \times 10^{3}$ PBMCs, and one of threefold dilutions of germline C $\gamma 2$ transcript competitor from $1.0 \times 10^{-1}$ attomole to $1.4 \times 10^{-4}$ attomole. The equivalent point was determined by polyacrylamide-gel electrophoresis.

Quantitative PCR for mature $C \gamma 2$ transcript. To amplify the mature $C \gamma 2$ transcript specifically, we prepared a common 5 ' primer for JH1, JH4, and JH5 genes, JHS (12). PCR amplification of the mature $\mathrm{C} \gamma 2$ transcript was carried out with JHS and HA1 primers, and cycling conditions were as follows: $94^{\circ} \mathrm{C}$ for $1 \mathrm{~min}, 56^{\circ} \mathrm{C}$ for $1 \mathrm{~min}$, and $72^{\circ} \mathrm{C}$ for $2 \mathrm{~min}$, for 35 cycles. The competitor DNA for mature $\mathrm{C} \gamma 2$ transcript was generated as follows: the plasmid containing 335-bp cDNA from the mature $\mathrm{C} \gamma 2$ transcript was partially substituted with the 233-bp Sty I fragment from interleukin-12 receptor cDNA, and was used as a competitor DNA. The PCR product of the wild-type is $335 \mathrm{bp}$, and that of the competitor is $301 \mathrm{bp}$. Each template contained the same amounts of cDNA from RNA extracted from $7.3 \times 10^{3}$ PBMCs and one of several tenfold dilutions of mature $\mathrm{C} \gamma 2$ transcript competitor from $1.0 \times 10^{1}-1.0 \times 10^{-5}$ attomole. The equivalent point was determined by polyacrylamide gel electrophoresis.

Amplification of the genomic $S \gamma 2$ region. Genomic DNA was purified from a polynuclear cell fraction with a Sepa Gene (Sanko Jyunyaku, Tokyo, Japan) according to the manufacturer's instruction.
Nested PCR amplification of genomic region for $\mathrm{S} \gamma 2$ was carried out with IS2 and HA2 primers (first PCR), SS and SA primers (second PCR), and cycling conditions as follows: $94^{\circ} \mathrm{C}$ for $1 \mathrm{~min}, 65^{\circ} \mathrm{C}$ for 2 min, $72^{\circ} \mathrm{C}$ for $6 \mathrm{~min}$ for 40 cycles (first PCR), $94^{\circ} \mathrm{C}$ for $1 \mathrm{~min}, 65^{\circ} \mathrm{C}$ for $2 \mathrm{~min}$, and $72^{\circ} \mathrm{C}$ for $4 \mathrm{~min}$ for 40 cycles (second PCR).

Amplification of the genomic $C \gamma 2$ region. PCR amplification of genomic region for $\mathrm{C} \gamma 2$ was carried out with $\mathrm{CS} 1$ and $\mathrm{CA}$ primers and cycling conditions as follows: $94^{\circ} \mathrm{C}$ for $1 \mathrm{~min}, 60^{\circ} \mathrm{C}$ for $1 \mathrm{~min}, 72^{\circ} \mathrm{C}$ for $5 \mathrm{~min}$ for 5 cycles; and $94^{\circ} \mathrm{C}$ for $1 \mathrm{~min}, 60^{\circ} \mathrm{C}$ for $2 \mathrm{~min}$, and $72^{\circ} \mathrm{C}$ for 2 min for 40 cycles.

Cloning of $M$ exons for $m \gamma 2 \mathrm{HC}$. Human $\mathrm{C} \gamma 2$ gene cloned by a Charon 4A phage was kindly donated by Dr. T. Honjo (Kyoto University; 13). We subcloned a 6.4-kb Hind III fragment including Cy2 exons to pTZ18U (United States Biochemical Corp., Cleveland, $\mathrm{OH}$ ) from the phage clone. We prepared the primers on exon 4 of $\mathrm{C} \gamma 2$ and the highly conserved sequence of human $\gamma \mathrm{M} 2$ exons (MA; 14, 15). Cycle conditions were as follows: $94^{\circ} \mathrm{C}$ for $1 \mathrm{~min}, 65^{\circ} \mathrm{C}$ for $2 \mathrm{~min}$, and $72^{\circ} \mathrm{C}$ for $5 \mathrm{~min}$ for 40 cycles. The fragment was cloned into pT7Blue T-vector (Novagen, Inc., Madison, WI) and analyzed.

Amplification of $c D N A$ for $m \gamma 2 H C$. Complementary DNA for m $\gamma 2 \mathrm{HC}$ was amplified with $\mathrm{HS}$ and MA primers and cycling conditions as follows: $94^{\circ} \mathrm{C}$ for $1 \mathrm{~min}, 65^{\circ} \mathrm{C}$ for $2 \mathrm{~min}$, and $72^{\circ} \mathrm{C}$ for $5 \mathrm{~min}$ for 40 cycles.

\section{Results}

Quantitative reverse transcription (RT)-PCR for germline $C \gamma 2$ transcript. Expression of germline transcripts of each constant $\mathrm{H}$ region, except for $\mathrm{C} \delta$, is apparently essential for class switch recombination $(16,17)$. The germline $\mathrm{C} \gamma 2$ transcript was reported to be expressed spontaneously in PBMCs (18). We prepared 5' I $\gamma 2$ and 3' C $\gamma 2$ specific primers (Fig. 1), and quantitative RT-PCR for germline $\mathrm{C} \gamma 2$ transcript was carried out. The relative quantities of germline $\mathrm{C} \gamma 2$ transcript were assayed by the equivalent points of competitive PCR in the polyacrylamide-gel electrophoresis patterns (Fig. $2 \mathrm{~A}$ ). Proband's target cDNAs and competitor were almost equivalent at $3.3 \times 10^{-2}$ attomole, and those of a control were also equivalent at $3.3 \times$ $10^{-2}$ attomole. As shown in Fig. $2 C$, the relative quantity of germline $\mathrm{C}_{\gamma} 2$ transcript, determined at the equivalent points 


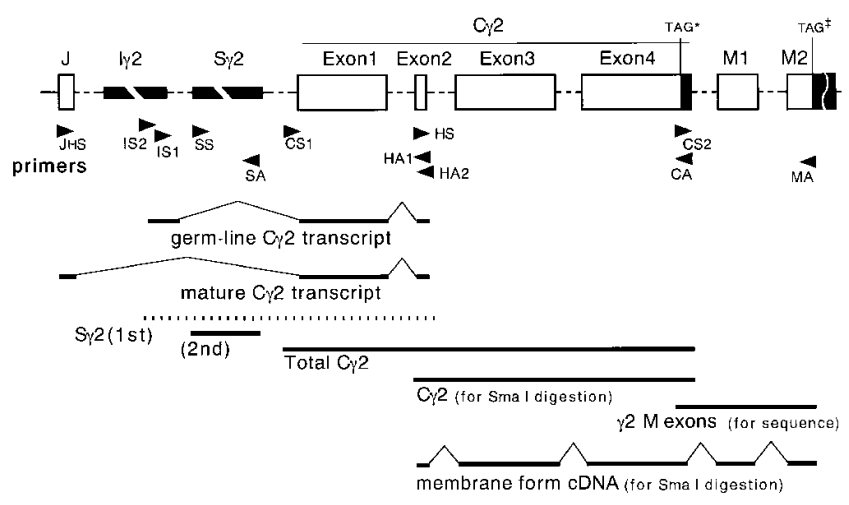

Figure 1. Schematic diagram of PCR strategies. I $\gamma 2$ and $\mathrm{S} \gamma 2$ regions are indicated by thick bars. Coding exons are indicated by open boxes. 3' Noncoding regions corresponding to secreted and membrane-bound forms of $\mathrm{C} \gamma 2 \mathrm{cDNAs}$ are indicated by solid boxes. Termination codons of the secreted form $(*)$ and membrane form $(*)$ are marked. Primers are indicated by arrowheads, and their names and sequences are given in Table I. PCR fragments amplified from genomic DNA are indicated by thick lines. The PCR fragment amplified by the first step of nested PCR of S $\gamma 2$ is indicated by broken thick lines. PCR fragments amplified from cDNA are indicated by fragmented thick lines.

in this competitive PCR, showed no apparent difference between patients and controls.

Quantitative RT-PCR for mature C $\gamma 2$ transcript. Since spontaneous IgG2 production in PBMCs can occur (19), spontaneous expression of mature $\mathrm{C} \gamma 2$ transcript can also be expected. To amplify the mature $\mathrm{C} \gamma 2$ transcript specifically, we set a sense primer on the conserved sequence for $\mathrm{JH} 1, \mathrm{JH} 4$, and JH5 genes (12), and an antisense primer on the hinge region of C $\gamma 2$ gene (Fig. 1) and performed quantitative PCR as shown in Fig. $2 \mathrm{~B}$. Proband's target cDNAs and competitor were almost equivalent between $1.0 \times 10^{-4}$ and $1.0 \times 10^{-5}$ attomole, and those of a control were almost equivalent between $1.0 \times 10^{-1}$ and $1.0 \times 10^{-2}$ attomole (Fig. $2 \mathrm{~B}$ ). The mature transcript levels in both patients were reduced to about one-hundredth or one-thousandth of the level of the controls (Fig. 2C).

Taken together with the normal expression level of germline transcript, the defect was thought to lie at or after the class switch recombination step. We also amplified the genomic Sy2 region specifically from the proband and from controls (Fig. 1), however, no apparent size difference was detected in the amplified fragments (data not shown).

Amplification and sequencing of genomic $C \gamma 2$ region. Because of the high degree of homology between the human $\mathrm{C} \gamma 1, \mathrm{C} \gamma 2$, $\mathrm{C} \gamma 3$, and $\mathrm{C} \gamma 4$ genes (the percentage of homology in the coding regions is $95.3-97 \%$, with a homology of $93.3-95 \%$ in noncoding areas; 20), we designed a pair of primers that would specifically amplify the C $\gamma 2$ gene (Fig. 1). The product of the proband's $\mathrm{C} \gamma 2$ region, which includes exons $1-4$ for the $\mathrm{C} \gamma 2$ gene, was entirely sequenced.

When the nucleotide is numbered according to the database EMBL J00230, the termination codon of the secreted form of $\gamma 2 \mathrm{H}$ chain (s $\gamma 2 \mathrm{HC}$ ) is ${ }^{1800} \mathrm{TGA}$. We identified onebase replacement from $\mathrm{T}$ to $\mathrm{C}(1790 \mathrm{~T} / \mathrm{C})$, and one-base insertion of $\mathrm{G}$ between nucleotide numbers 1792 and 1793 (1793insG) in the proband (Fig. $3 \mathrm{~A}$ ). Sequence analysis revealed that both $1790 \mathrm{~T} / \mathrm{C}$ and 1793 ins $\mathrm{G}$ were detected homozygously in both the patients' DNAs, heterozygously in their mother's DNA, but not detected in 28 healthy controls. These two mutations, which had only a 3-bp distance from each other, were linked in the alleles tested. Therefore, using 1790T/C, which creates a new Sma I site, we screened genomic DNAs of 65 independent normal controls (130 alleles), but detected no 1790T/C mutant allele (Fig. 3 B). 1790T/C causes no amino acid change, and 1793insG causes only a deletion of the last lysine residue in s $2 \mathrm{HC}$ by a frame shift (Fig. $4 A$ ).

Cloning and sequencing $M$ exons for $m \gamma 2 H C$. To assess the effects of these mutations on $\mathrm{m} \gamma 2 \mathrm{HC}$, we cloned and sequenced the two $\mathrm{M}$ exons for $\mathrm{m} \gamma 2 \mathrm{HC}$. Sequences of $\gamma 2 \mathrm{M}$
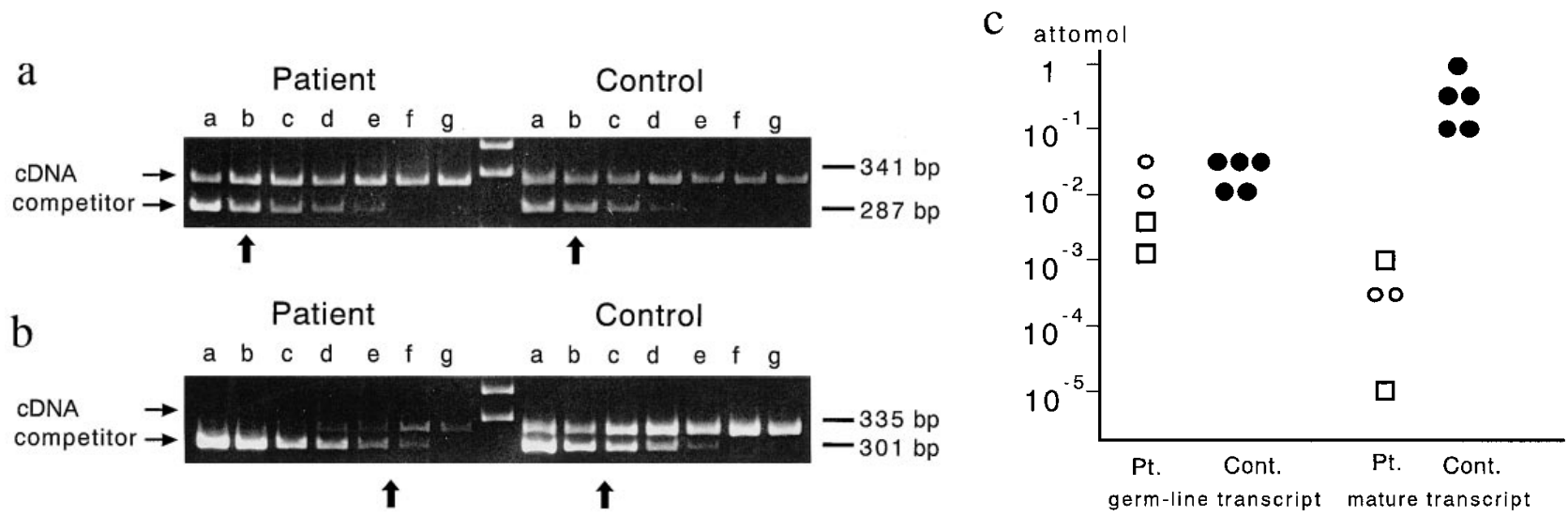

Figure 2. (a) Competitive PCR for the germline $\mathrm{C} \gamma 2$ transcript. Each template contained the same amounts of cDNA from RNA extracted from $7.3 \times 10^{3}$ PBMCs and one of threefold dilutions of germline $\mathrm{C} \gamma 2$ transcript competitor from $1.0 \times 10^{-1}-1.410^{-4}$ attomole (lanes $a-g$ ). Target cDNA and competitor were almost equivalent at $3.3 \times 10^{-2}$ attomole (lane $b$ ) in both the proband and a control, as indicated by arrows. $(b)$ Competitive PCR for mature $\mathrm{C} \gamma 2$ transcript. Each template contained the same amounts of cDNA from RNA extracted from $7.3 \times 10^{3}$ PBMCs and one of tenfold dilutions of mature $\mathrm{C} \gamma 2$ transcript competitor from $1.0 \times 10^{1}-1.0 \times 10^{-5}$ attomole (lanes $a-g$ ). The probands' target cDNAs and competitor were almost equivalent between $1.0 \times 10^{-4}$ (lane $e$ ) and $1.0 \times 10^{-5}$ attomole (lane $f$ ), and those of a control were almost equivalent between $1.0 \times 10^{-1}$ (lane $b$ ) and $1.0 \times 10^{-2}$ attomole (lane $c$ ) as indicated by arrows. (c) The expression levels of germline and mature C 22 transcripts were plotted logarithmically. $\bigcirc$, patient $1 ; \square$, patient $2 ; \bullet$, controls. 
a

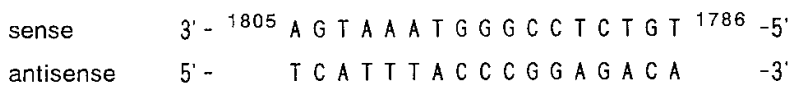

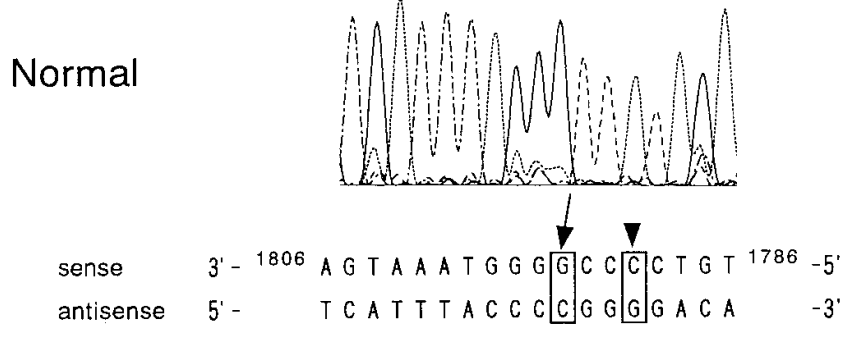

\section{Proband}

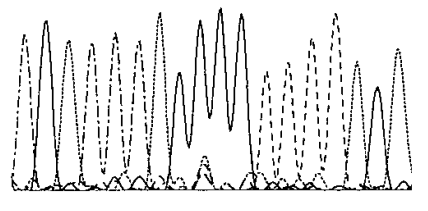

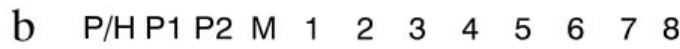

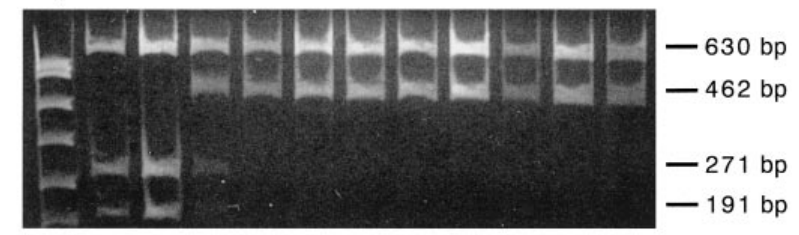

C

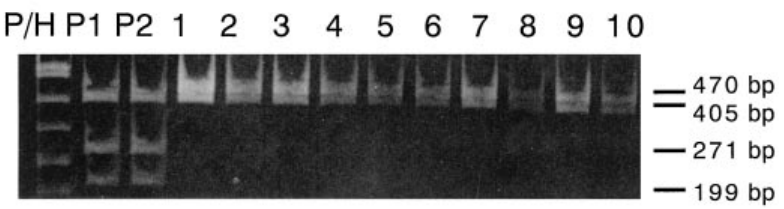

Figure 3. (a) Sequence analysis of the $\mathrm{C} \gamma 2$ gene (antisense patterns). The proband sequence had a ${ }^{1790} \mathrm{~T}$ to $\mathrm{C}$ substitution (1790T/C; arrowhead) and a ${ }^{1793} \mathrm{G}$ insertion (1793insG; arrow). ( $b$ and $c$ ) Sma I-digested PCR products of $\mathrm{C} \gamma 2$ region from genomic DNA $(b)$ and cDNA for $\mathrm{m} \gamma 2 \mathrm{HC}(c) . P / H$, size marker; $P 1$ and $P 2$, patients; $M$, their mother; $1-10$, controls. The PCR product from genomic DNA is $1092 \mathrm{bp}$ long and yields the expected 630- and 462-bp fragments (normal) or 630-, 271-, and 191-bp fragments (mutant) after Sma I digestion. The PCR product from cDNA is $875 \mathrm{bp}$ long and yields the expected 470- and 405-bp fragments (normal) or 405-, 271-, and 199-bp fragments (mutant) after Sma I digestion. In case of the cDNA, both1790T/C and 1793insG are required for Sma I digestion (see $a$ ).

exons (DDBJ, EMBL, and GenBank accession numbers AB006775 and AB006776) were highly homologous to those of other $\gamma \mathrm{M}$ exons $(14,15)$. The $\gamma 2 \mathrm{M} 1$ exon was identified $\sim 1.1 \mathrm{kbp}$ downstream from the termination codon for sy2HC. The M2 exon started $447 \mathrm{bp}$ downstream from the last base of M1 exon.

Amplification of $c D N A$ for $m \gamma 2 H C$. Thereafter, we designed a pair of primers so that the cDNA for m $\gamma 2 \mathrm{HC}$ was specifically amplified (Fig. 1). The cDNAs were successfully amplified in controls and in both patients. The alternative splice site was found at ${ }^{1794} \mathrm{G} / \mathrm{GT}$ in the $\mathrm{C} \gamma 2$ exon 4 just downstream from the mutation site (Fig. $4 A$ ). Hence, 1793 insG resulted in a frame shift of mRNA for $m \gamma 2 \mathrm{HC}$, causing complete changes of amino acid sequence encoded by M1 and M2 exons and generated an abnormal 117 amino acid sequence (Fig. 4, $A$ and $B)$. The cDNAs for $\mathrm{m} \gamma 2 \mathrm{HC}$ were then subjected to Sma I restriction assay. As expected, the mutations were homozygous in both patients' cDNAs, but the mutations were nil in 20 healthy controls' cDNAs (Fig. $3 C$ ).

\section{Discussion}

We cloned M1 and M2 exons for m $\gamma 2 \mathrm{HC}$, identified the alternative splice site in $\mathrm{C} \gamma 2$ exon 4 for $\mathrm{M}$ exons, and showed that 1793insG in $\mathrm{C} \gamma 2$ exon 4 caused a frame shift in $\mathrm{m} \gamma 2 \mathrm{HC}$ that resulted in complete changes of amino acid sequence encoded by M1 and M2 exons. We propose that 1793 insG is the cause of complete and selective IgG2 deficiency in these two Japanese siblings. Since the heterozygous mother had a normal IgG2 level, this mutation is unlikely to account for the large number of individuals with a low IgG2 level.

There are at least two possibilities that would explain the mechanism of $\mathrm{IgG} 2$ deficiency with the frame shift of $\mathrm{m} \gamma 2 \mathrm{HC}$. One is that this mutation results in complete loss of function and structure as a BCR, and the mutant $\mathrm{m} \gamma 2 \mathrm{HC}$ never appears on the B cell surface. The other is that the mutant my2HC, which lost the conserved motif in the cytoplasmic tail, could be expressed on the B cell surface; however, it could not complete the signal transduction or antigen processing. It was conceivable that the first case was the counterpart of mice lacking the transmembrane and cytoplasmic domains of $m \gamma 1 \mathrm{HC}$ or $\mathrm{m} \in \mathrm{HC}$, and the latter case was mice lacking most of the cytoplasmic tail of $\mathrm{m} \gamma 1 \mathrm{HC}$ or $\mathrm{m} \epsilon \mathrm{HC}$, respectively $(3,4)$. The levels of serum $\mathrm{IgG1}$ and $\mathrm{IgE}$ were reduced to a lesser extent in mice lacking the transmembrane domains than in mice lacking partial cytoplasmic domains. Because of a complete deficiency of serum IgG2, it seems likely that the patient's B cells could not express $\mathrm{m} \gamma 2 \mathrm{HC}$ on the surface. Hydropathy profile of normal and mutant sequences encoded by $\mathrm{M}$ exons was investigated according to Kyte and Doolittle (21). The average hydropathy of 19-residue segments of normal m $\gamma 2 \mathrm{HC}$ transmembrane domain was $>+2$, satisfying a condition of membrane-spanning sequences. On the other hand, most of the mutant sequence encoded by $\mathrm{M}$ exons was hydrophilic, and the average hydropathy of any 19-residue segment of the mutant sequence was $<+1.2$, which strongly suggests that there is no membranespanning sequence in the mutant sequence (data not shown).

Weiser et al. reported that transformed B cells expressing an $\mathrm{IgG} 2 \mathrm{a}$ BCR require the cytoplasmic tail of $\gamma 2 \mathrm{a}$, and specifically a tyrosine-based motif in this structure (5) that is also present in human $\mathrm{m} \gamma 2 \mathrm{HC}$ for efficient presentation of antigen to $T$ cells after surface immunoglobulin-mediated internalization. The frame shift mutation lost the tyrosine-based motif (5). Based on these results in mice, we conclude that the frame shift of $\mathrm{m} \gamma 2 \mathrm{HC}$ caused by 1793 insG resulted in a complete and selective $\mathrm{IgG} 2$ subclass deficiency.

The above cases including our case were those of a selective immunoglobulin deficiency. Cases of defects in the $\mu \mathrm{H}$ chain were also noted both in mice and humans. In a model mouse with a disrupted $\mathrm{M}$ exon of the $\mu \mathrm{H}$ chain gene, a complete absence of $\mathrm{B}$ cell production and profound hypogammaglobulinemia were evident (22). Mutations in the $\mu \mathrm{H}$ chain gene were also identified in patients with agammaglobulinemia who did not have mutations in Bruton's tyrosine kinase (23). These observations mean that an intact membranebound $\mu \mathrm{H}$ chain, which mediates signals into pro-B cells via 

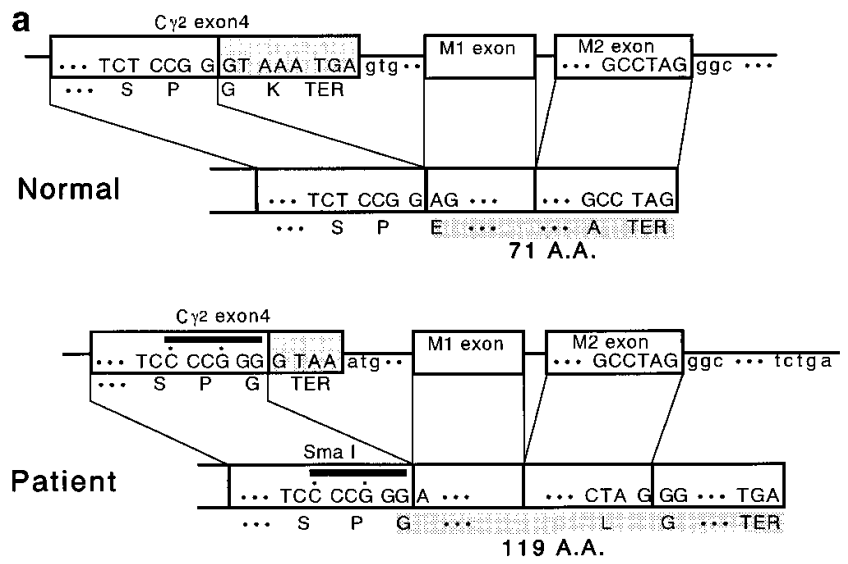

b

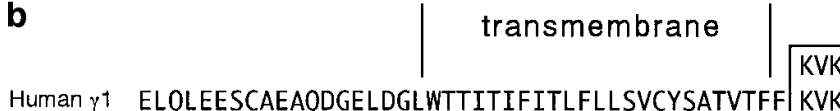

Human $\gamma 1$ ELQLEESCAEAQDGELDGLWTTITIFITLFLLSVCYSATVTFF
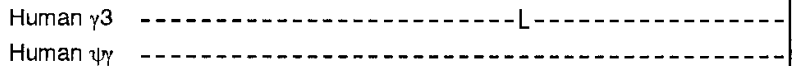

Human y2 -...-.-.--

Mutant $\gamma_{2}$ GAATGGELCGGAGRGAGRAVDDHHHLHHTLPAKRVLQCHHHLL QGE
Figure 4. (A) Diagram of the last exon (exon 4) and M exons for $\mathrm{m} \gamma 2 \mathrm{HC}$. The $\mathrm{COOH}$ terminal of s $\gamma 2 \mathrm{HC}$ is marked by a shadowed box, and that of $\mathrm{m} \gamma 2 \mathrm{HC}$ is marked by shadowed amino acid sequences. The1790T/C and 1793insG are shown by dotted letters. Just before the alternative splice site, the new Sma I site was introduced in the mutant (black bars). (B) Amino acid sequences encoded by M exons for human $\gamma \mathrm{H}$ chains. The one base insertion results in a frame shift of $\mathrm{m} \gamma 2 \mathrm{HC}$, and generates a completely different amino acid sequence of the transmembrane and intracellular portion. The hydrophobic amino acids cluster and conserved cytoplasmic tail residues (Lys-Val-Lys motif and Tyr-X-X-Met motif) are absent in the mutant sequence. Nucleotide sequences around $\mathrm{M} 1$ and $\mathrm{M} 2$ exons for $\mathrm{m} \gamma 2 \mathrm{HC}$ will appear in the DDBJ, EMBL, and GenBank nucleotide sequence databases with accession numbers AB006775 and AB006776.

\section{cytoplasmic}

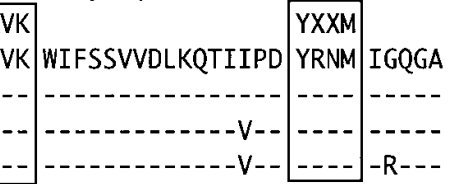

VDLLLSGGPEADHR-R LQEH DQA-GLGPPSVGCPGPPRPHTGAVGHAQP SPRPHLPPTSPPSTPWLSGLAVAL
$\mathrm{BCR}$, is essential for B cell development in both mice and humans. The efficient primary and secondary immunoglobulin responses depend on the appropriate expression of the membrane-bound form of the $\mathrm{H}$ chain in humans as well as mice.

\section{Acknowledgments}

We thank Dr. T. Honjo (Kyoto University) for the generous gift of a human $\mathrm{C} \gamma 2$ gene clone and $\mathrm{M}$. Ohara for helpful comments.

This study was supported in part by Grants-in-Aid for Scientific Research from the Ministry of Education, Science, Sports, and Culture of Japan.

\section{References}

1. Reth, M. 1992. Antigen receptors on B lymphocytes. Annu. Rev. Immunol. 10:97-121.

2. Esser, C., and A. Radbruch. 1990. Immunoglobulin class switching: molecular and cellular analysis. Annu. Rev. Immunol. 8:717-735.

3. Kaisho, T., F. Schwenk, and K. Rajewsky. 1997. The roles of $\gamma 1$ heavy chain membrane expression and cytoplasmic tail in IgG1 responses. Science. 276:412-415.

4. Achatz, G., L. Nitschke, and M.C. Lamers. 1997. Effect of transmembrane and cytoplasmic domains of IgE on the IgE response. Science. 276:409-411.

5. Weiser, P., R. Müller, U. Braun, and M. Reth. 1997. Endosomal targeting by the cytoplasmic tail of membrane immunoglobulin. Science. 276:407-409.

6. Smith, C.I.E., L. Hammarström, J.I. Henter, and G.G.D. Lange. 1989. Molecular and serologic analysis of IgG1 deficiency caused by new forms of the constant region of the Ig H chain gene deletions. J. Immunol. 142:4514-4519.

7. Shackelford, P.G., D.M. Granoff, S.H. Polmar, M.G. Scott, M.C. Goskowicz, J.V. Madassery, and M.H. Nahm. 1990. Subnormal serum concentrations of IgG2 in children with frequent infections associated with varied patterns of immunologic dysfunction. J. Pediatr. 116:529-538.

8. Inoue, R., N. Kondo, Y. Kobayashi, O. Fukutomi, and T. Orii. 1995. IgG2 deficiency associated with defects in production of interferon-gamma; comparison with common variable immunodeficiency. Scand. J. Immunol. 41:130-134.

9. Chua, A.O., R. Chizzonite, B.B. Desai, T.P. Truitt, P. Nunes, L.J. Minetti, R.R. Warrier, D.H. Presky, J.F. Levine, M.K. Gately, and U. Gubler. 1994. Expression cloning of a human IL-12 receptor component. J. Immunol.
153:128-135.

10. Mills, F.C., M.P. Mitchell, N. Harindranath, and E.E. Max. 1995. Human Ig $\mathrm{S} \gamma$ regions and their participation in sequential switching to IgE. J. Immunol. 155:3021-3036.

11. Ellison, J., and L. Hood. 1982. Linkage and sequence homology of two human immunoglobulin $\gamma$ heavy chain constant region genes. Proc. Natl. Acad. Sci. USA. 79:1984-1988.

12. Ravetch, J.V., U. Siebenlist, S. Korsmeyer, T. Waldmann, and P. Leder, 1981. Structure of the human immunoglobulin $\mu$ locus: characterization of embryonic and rearranged J and D genes. Cell. 27: 583-591.

13. Takahashi, N., S. Ueda, M. Obata, T. Nikaido, S. Nakai, and T. Honjo. 1982. Structure of human immunoglobulin gamma genes: implications for evolution of a gene family. Cell. 29:671-679.

14. Kinoshita, K., A. Shimizu, and T. Honjo. 1991. The membrane exons of the pseudo- $\gamma$-chain gene of the human immunoglobulin are apparently functional and highly homologous to those of the $\gamma 1$ gene. Immunol. Lett. 27:151-155.

15. Bensmana, M., and M.P. Lefranc. 1990. Gene segments encoding membrane domains of the human immunoglobulin gamma 3 and alpha chains. Immunogenetics. 32:321-330.

16. Stavnezer-Nordgren, J., and S. Sirlin. 1986. Specificity of immunoglobulin heavy chain switch correlates with activity of germline heavy chain genes prior to switching. EMBO J. 5:95-102.

17. Yancopoulos, G.D., R.A. DePinho, K.A. Zimmerman, S.G. Lutzker, N. Rosenberg, and F.W. Alt. 1986. Secondary genomic rearrangement events in pre- $\mathrm{B}$ cells. $\mathrm{V}_{\mathrm{H}} \mathrm{DJ}_{\mathrm{H}}$ replacement by a LINE-1 sequence and directed class switching. EMBO J. 12:3259-3266.

18. Kitani, A., and W. Strober. 1993. Regulation of Cy subclass germ-line transcripts in human peripheral blood B cells. J. Immunol. 151:3478-3488.

19. Kawano, Y., T. Noma, and J. Yata. 1994. Regulation of human IgG subclass production by cytokines. J. Immunol. 153:4948-4958.

20. Huck, S., P. Fort, D.H. Crawford, M.P. Lefranc, and G. Lefranc. 1986. Sequence of a human immunoglobulin gamma 3 heavy chain constant region gene: comparison with the other human C $\gamma$ genes. Nucleic Acids Res. 14:17791789.

21. Kyte, J., and R.F. Doolittle. 1982. A simple method for displaying the hydropathic character of a protein. J. Mol. Biol. 157:105-132.

22. Kitamura, D., J. Rose, R. Kühn, and K. Rajewsky. 1991. A B cell-deficient mouse by targeted disruption of the membrane exon of the immunoglobulin $\mu$ chain gene. Nature. 350:423-426.

23. Yel, L., Y. Minegishi, E. Coustan-Smith, R.H. Buckley, H. Trübel, L.M. Pachman, G.R. Kitchingman, D. Campana, J. Rohrer, and M.E. Conley. 1996. Mutations in the mu heavy-chain gene in patients with agammaglobulinemia. N. Engl. J. Med. 335:1486-1493. 